\title{
TV UERJ: conhecimento sem fronteiras em uma webtv universitária
}

\author{
Uerj TV: knowledge without borders in a university WebTV
}

\begin{abstract}
Ana Cláudia Theme ${ }^{1}$, Anderson Barreto Autor ${ }^{2}$, Guto Lacerda ${ }^{3}$
1 Jornalista, mestre em Ciência Política, doutoranda em História Política. Diretora do Centro de Tecnologia Educacional, Subreitoria de Extensão e Cultura da Universidade do Estado do Rio de Janeiro (UERJ), Brasil. E-mail: atheme@gmail.com 2 Jornalista, especializado em Educação e Tecnologia, mestrando em Psicanálise, Saúde e Sociedade. Centro de Tecnologia Educacional, Sub-reitoria de Extensão e Cultura da Universidade do Estado do Rio de Janeiro (UERJ), Brasil. E-mail: jornalistaa@hotmail.com

3 Jornalista, especializado em Jornalismo Cultural e mestre em Comunicação Social. Centro de Tecnologia Educacional, Sub-reitoria de Extensão e Cultura da Universidade do Estado do Rio de Janeiro (UERJ), Brasil. E-mail: gutolacerda@hotmail.com
\end{abstract}

Recebido em: 31/03/2015 | Aprovado em: 30/03/2017

DOI: 10.12957/interag.2017.15884

\begin{abstract}
Resumo
O intenso progresso científico e tecnológico conquistado durante o século $X X$ alcança uma inédita expressão com o limiar do século XXI, suscitando novas questões na era das redes. Os tradicionais produtores e mediadores de informação e cultura - entre eles a escola, os meios de comunicação, o poder público e as universidades - veem-se desafiados a rediscutir suas práticas. E a assimilar, a seu favor, as novidades, de modo a atuar dinamicamente nesse espaço público reconfigurado pelas tecnologias digitais e em acelerada transformação. É nesse complexo cenário que se insere a criação da webtv da Universidade do Estado do Rio de Janeiro, em 2011. Elaborada por profissionais de comunicação, professores e estudantes, a TV Uerj articula ensino, pesquisa e extensão ao divulgar a produção universitária científica, cultural e artística.
\end{abstract}

Palavras-chave: Webtv; Webtv Universitária; Difusão Científica Online; Mídias Sociais

\begin{abstract}
The intense scientific and technological progress achieved during the 20th century reaches an unprecedented scale on the brink of the 21th century, and raises new questions in the internet era. The traditional producers and mediators of information and culture - such as schools, means of communication, governments and universities - are being challenged to review their practices and to incorporate the novelties, in order to dynamically take part in the public arena that has been reconfigured by digital technologies and that is quickly changing. In this complex scenario the Rio de Janeiro State University (UERJ) webtv is created, in 2011, by a team of communication professionals, professors and students. UERJ TV combines teaching, research and extension through the publication of the university's scientific, cultural and artistic production.
\end{abstract}

Keywords: Webtv; University Webtv, On line Scientific Publication; Social Media.

Área temática: Comunicação

Linha de extensão: Jornalismo, Mídias 


\section{Introdução}

Ao longo do século XX, o desenvolvimento dos meios de comunicação de massa suscitou inúmeros desdobramentos na vida social, intelectual e política, a partir da introdução de novas formas de publicidade mediada. Antes, o conhecimento acerca dos indivíduos ou dos fatos estava relacionado ao compartilhamento de um lugar comum e baseava-se na interação face a face, com seu caráter dialógico. ${ }^{1}$

O advento da imprensa criou o público leitor - uma nova categoria deslocada no tempo e no espaço, não mais definida pelo estar simultâneo em um local, mas sim pelo acesso à publicidade mediada pela palavra impressa: um acontecimento não precisava mais ser presenciado para tornar-se público. ${ }^{2}$

Ao atuar como produtores e enunciadores de representações sobre o real, os meios de comunicação constituem-se em competidores, ao lado de outros agentes sociais, numa arena onde se disputa a produção do senso comum. Ou, nas palavras de Bourdieu, "o monopólio da nomeação legítima como imposição oficial - isto é, explícita e pública da visão legítima do mundo social. ${ }^{3}$

Trata-se de uma luta simbólica para influenciar as percepções coletivas acerca da realidade, na qual os meios agem, simultaneamente, como esfera mediadora do debate público e como fonte de informação/produção de versões sobre a realidade. O que está permanentemente em jogo é a elaboração discursiva de diferentes segmentos da sociedade - entre eles, as universidades -, empenhados em produzir e divulgar suas próprias narrativas acerca de diferentes temas.

As possibilidades de informação e participação ampliaram-se enormemente e os cidadãos de hoje testemunham o que ocorre em todo o mundo, no exato momento em que o fato se dá. Porém, se este expandido campo de visão constitui um avanço, igualmente significativo é o fato de que seja estruturado pelos meios de comunicação de massa, com seus processos típicos de seleção, produção de imagens e conteúdos, edição e transmissão. 
No limiar do século XXI, o surgimento de inovadoras tecnologias de informação e comunicação amplia exponencialmente esse panorama. $\mathrm{O}$ mundo das economias globalizadas dilui as fronteiras geográficas ao mesmo tempo em que acena com infinitas possibilidades de conexão: entre os povos, países, culturas, cientistas, artistas, educadores, tribos urbanas e localidades remotas. ${ }^{4}$

A velocidade e a abrangência das novas modalidades de comunicação instigam tanto o cidadão comum quanto o pesquisador a experimentar e incorporar as tecnologias digitais, ao alcance de um simples toque na tela de um dispositivo móvel - um passaporte instantâneo para virtualmente qualquer lugar do planeta, a qualquer momento.

A emergência de novos temas trouxe interrogações de natureza técnica, científica, ética e social. Mudanças climáticas, alimentos transgênicos, variadas configurações familiares, migrações, terapia genética... uma infinidade de questões mobiliza a opinião pública, inclusive no ciberespaço e nas mídias sociais. E exige, por parte das universidades e centros de pesquisa, intensa capacidade de produzir e difundir suas reflexões, práticas e estudos. $^{5}$

Nesse contexto, as atividades de extensão universitária apresentam-se como um ambiente de construção de conhecimento e troca de saberes, notadamente no que se refere ao estabelecimento de estratégias de comunicação capazes de oferecer novas possibilidades de intervenção no debate público. "A extensão universitária é processo educativo, cultural e científico que articula o Ensino e a Pesquisa de forma indissociável e viabiliza a relação transformadora entre a Universidade e a Sociedade”. ${ }^{6}$

Por meio de diferentes abordagens comunicacionais e da abertura de canais horizontais em mão dupla com a sociedade, essas instituições podem superar o isolamento que frequentemente caracteriza o ambiente acadêmico, tornando-se mais permeáveis a fim de construir uma relação dialógica com diversos atores sociais.

Outro desafio diante das universidades é a elaboração de suas próprias falas e conteúdos multimidiáticos, num cenário em que é preciso compreender e experimentar as dinâmicas formas de produzir audiovisual na contemporaneidade, marcada pela interação instantânea e não mais mediada exclusivamente pelos tradicionais veículos de 
massa - porém, acelerada e transformada por internet e mídias sociais. Esse conjunto de questionamentos e reflexões constituiu o ponto de partida para a criação da webtv da Uerj, projeto empreendido pelo Centro de Tecnologia Educacional da Universidade.

\section{O fazer televisivo em tempos de mudança de paradigma}

Vinculado à Sub-reitoria de Extensão e Cultura, o Centro de Tecnologia Educacional (CTE) é o órgão responsável pela produção audiovisual da Universidade. Com uma equipe multidisciplinar formada por docentes, funcionários administrativos, estudantes bolsistas, técnicos de áudio e vídeo, profissionais de pedagogia, jornalismo e relações públicas, atua na confluência dos campos da educação e da comunicação.

Entre suas atribuições, destacam-se: produção de vídeos educativos e institucionais; elaboração de programas de rádio e TV; registro em vídeo das atividades científicas, culturais e extensionistas; organização do banco de imagens e do acervo de memória Uerj.

Desde o ano 2000, essa produção televisiva era exibida via cabo no canal 11 da NetRio, por meio de um pool de emissoras universitárias públicas e particulares, reunidas no Canal Universitário do Rio de Janeiro (UTV). A Uerj situava-se, assim, entre as 151 instituições de ensino superior do país (53 delas na região sudeste) a contar com TV; entre elas, $52 \%$ adotavam o compartilhamento de sinal, de acordo com dados do Mapa da TV Universitária Brasileira. ${ }^{?}$

A exemplo da maioria das instituições com semelhante configuração, a produção televisiva da Uerj buscava diferenciar-se pela oferta de programas mais reflexivos, com a participação de professores da Universidade. No início de 2011, entretanto, por determinação da reitoria, a Uerj desligou-se do Canal Universitário e o CTE recebeu a incumbência de desenvolver uma nova plataforma para veicular a produção televisiva.

Dali por diante, tratava-se não apenas do desafio de criar uma TV universitária na internet, mas principalmente de promover uma mudança de paradigma no fazer televisivo, em sintonia com um movimento global que claramente aportara em definitivo no ciberespaço. 


\section{O processo rumo à web}

Os primeiros passos incluíram a identificação das especificidades da construção de conhecimento por meio da internet, bem como das novas formas de intercâmbio com um público que perdia seu caráter local para tornar-se virtualmente sem fronteiras. De que modo os conteúdos audiovisuais postados na grande rede poderiam ampliar o acesso aos saberes universitários? Como reverberar a pluralidade de reflexões presentes no ambiente informacional da internet, de modo a estimular uma necessária polifonia a favor da diversidade?

Por meio de uma metodologia capaz de contemplar premissas pertencentes tanto ao campo da divulgação científica quanto ao campo do telejornalismo on line como sistema peculiar de produção discursiva, procedeu-se a um estudo acerca das configurações desse recente segmento de televisão no Brasil. A perspectiva da Análise Documental permitiu o mapeamento das principais características e dos diversos modelos adotados por webtvs universitárias brasileiras, avaliando-se seu conteúdo, formatos e recursos tecnológicos por meio de abordagens qualitativas. ${ }^{8}$

$\mathrm{Na}$ etapa seguinte, a equipe engajou-se em um processo de reestruturação editorial da produção para adaptá-la à internet, onde o tempo de permanência do usuário on line é menor; há altas taxas de dispersão; a atenção do internauta é fragmentada, disputada em uma teia de hiperlinks. Todos os programas foram avaliados e reduzidos de meia hora de duração para uma média de até oito minutos. ${ }^{9}$

Através desse movimento reflexão-ação-reflexão, os profissionais, estudantes e técnicos reviram não só os programas, mas também suas próprias práticas, buscando desconstruir o modelo de TV tradicional aprendido para reconstruí-lo no novo paradigma digital da internet. Houve dúvidas, testes, experimentações, correções de rota e a necessária adaptação às novidades. Este momento foi relatado pela equipe como sendo o mais difícil do processo, porém também o mais enriquecedor. 


\section{TV Uerj: informação, cultura e diálogo}

A webtv iniciou suas atividades em outubro de 2011, ocasião em que o site estreou na internet ainda em fase de testes (www.tvuerj.com.br). Pouco depois fez-se presente também nas redes sociais, com a criação de canais no Youtube, fan pages no Facebook e perfil no Twitter.

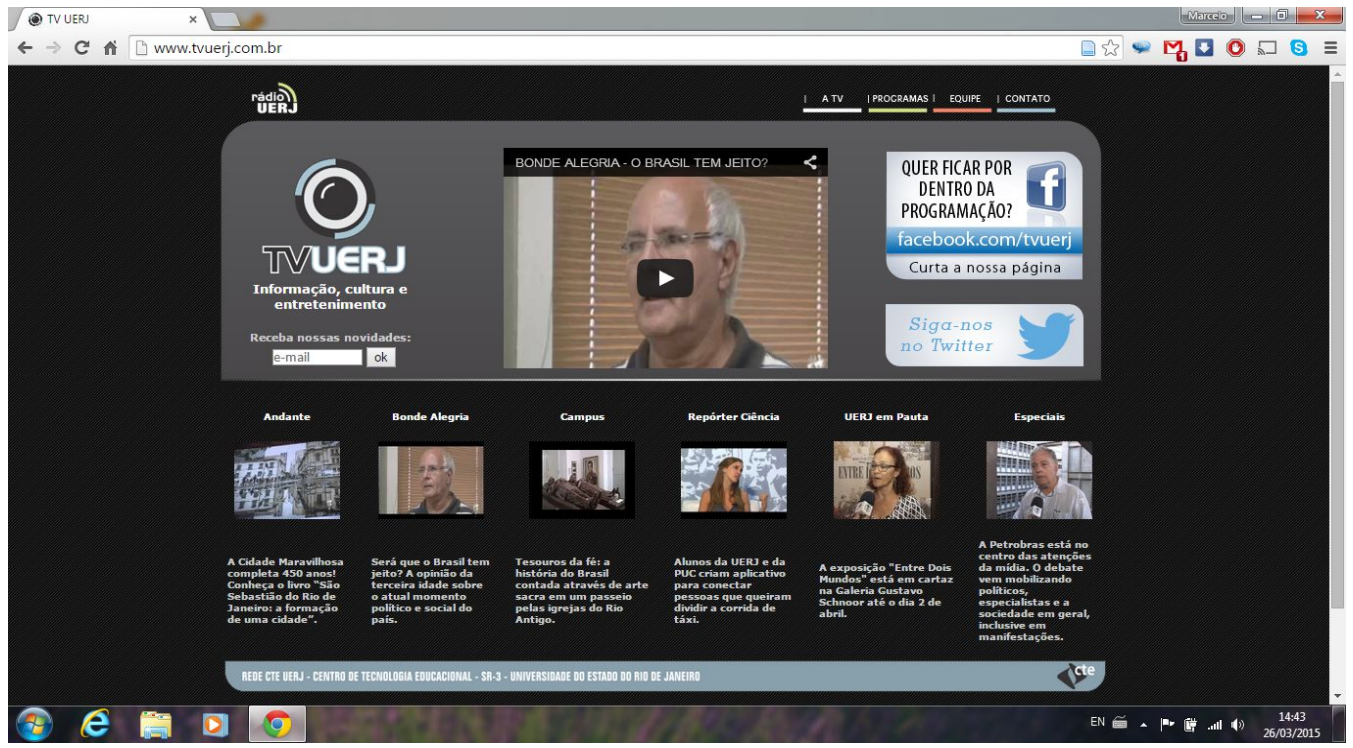

Figura [1]. Site da TV Uerj

Em 2012, como estratégia de divulgação da recém-lançada TV Uerj, o CTE organizou um concurso de vídeo e animação. O 1 Festival Curta na Uerj apostou na temática ambiental e recebeu trabalhos produzidos por adultos, crianças e jovens de nove estados brasileiros, elaborados com celular, máquina fotográfica e filmadora. Os participantes foram incentivados a refletir sobre a questão da ecologia e a produzir suas narrativas com técnicas e linguagens variadas. Todos os vídeos foram veiculados no site da TV Uerj e passaram por votação popular na internet.

Assim, a TV Uerj estabeleceu o intercâmbio entre a Universidade e a sociedade e contribuiu para dar visibilidade à produção de conteúdo do público, numa relação dialógica baseada no uso de novas tecnologias e na troca de diferentes saberes. A partir da indissociabilidade ensino-pesquisa-extensão, propiciou uma oportunidade de ação 
transformadora na realidade social. Em 2016, o Festival Curta na Uerj encontra-se na sua quinta edição.

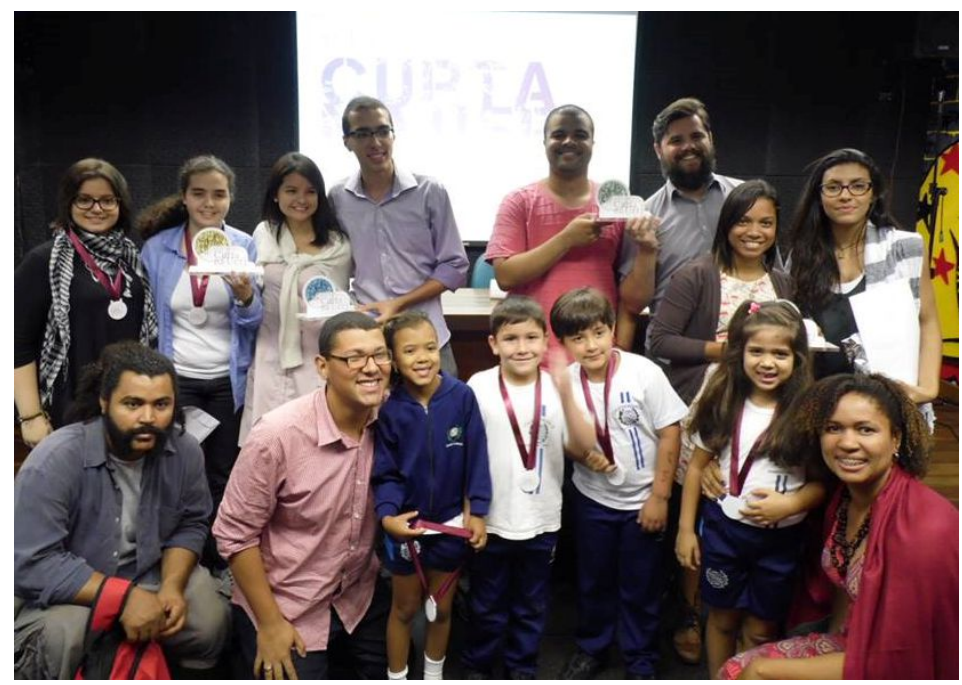

Figura [2]. Premiados do concurso

A grade de programação da TV Uerj compõe-se de seis produções voltadas à interdisciplinaridade e à reflexão crítica. Para o alcance desses objetivos, os programas debatem os temas em voga na sociedade ou, ainda, aqueles silenciados pela mídia tradicional, além de divulgar a produção acadêmica, extensionista, artística e cultural da Uerj.

Programa Campus - Trata-se de uma revista eletrônica de atualidades voltada ao diálogo entre a área acadêmica e diferentes realidades sociais. Já abordou gentrificação, eleições, migrações e mercado brasileiro de mídia, entre outros temas. Conquistou prêmios no Festival Cine e Vídeo de Gramado em 2007 e 2008. Em 2014, a edição intitulada "Convivendo com o HIV" ficou em primeiro lugar na categoria Trabalhos de Comunicação do $8^{\circ}$ Prêmio Visibilidade das Políticas Sociais, promovido pelo Conselho de Serviço Social do Rio de Janeiro.

Programa Bonde Alegria - É o único programa de TV brasileiro realizado com a efetiva participação de idosos, em uma parceria CTE/Universidade Aberta da Terceira Idade (UnATI/Uerj). Por meio do Bonde Alegria, A TV Uerj promove uma ação de visibilidade 
desta parcela da sociedade e realiza uma das missões da extensão universitária ao "voltar-se prioritariamente para os setores da população que vêm sendo sistematicamente excluídos dos direitos e da compreensão de cidadania". ${ }^{10}$

Programa Andante - Produção voltada à cena cultural brasileira e ao mundo das artes plásticas, música, teatro, literatura e fotografia. Constitui um espaço aberto às atividades culturais da Uerj, bem como às manifestações artísticas de grupos sociais minoritários, como quilombolas.

Programa Repórter Ciência - Dedicado à difusão científica e extensionista, é uma vitrine para projetos e iniciativas da Uerj em todas as áreas do conhecimento, das algas marinhas à genética, dos veículos offroad à história indígena.

Programa Uerj Em Pauta - Com a cobertura jornalística de palestras, exposições e congressos, o programa se propõe a democratizar o acesso da sociedade ao cotidiano universitário, inclusive com transmissões ao vivo. Um exemplo recente foi a visita do expresidente uruguaio Pepe Mujica à Uerj, em 27/8/15. A TV Uerj foi o único canal (além da Mídia Ninja) a transmitir o evento pela internet durante três horas, atendendo à expectativa do público que não foi contemplado pelas emissoras comerciais tradicionais. Estas fizeram apenas rápidos registros, cujo enquadramento de viés reducionista limitouse à política uruguaia de descriminalização das drogas.

Em quatro anos, a TV Uerj produziu e veiculou 782 edições de seus programas; transmitiu ao vivo pela internet 97 atividades universitárias, constituindo uma alternativa a quem busca informação no ciberespaço. De acordo com as estatísticas do Google Analytics, o site da TV Uerj recebeu mais de 200 mil visualizações.

Essa produção audiovisual busca acompanhar a crescente relevância comunicacional da internet e das mídias sociais, valorizando-as como interfaces imediatas com diversos públicos. A participação no Youtube, Twitter e Facebook vem demonstrando crescimento, com as postagens nesse último alcançando mais de sete mil leitores por semana. 


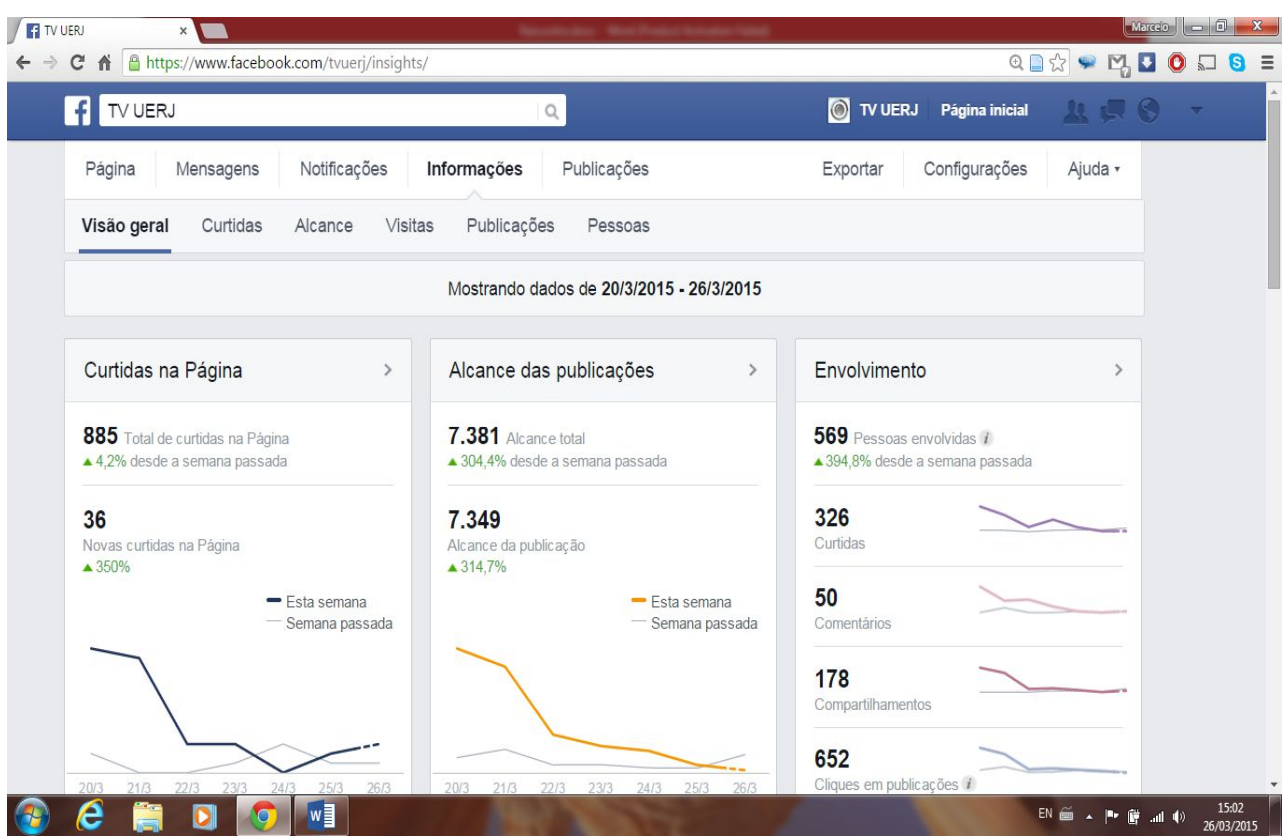

Figura [3]. Post do Facebook. Dados de março/2015

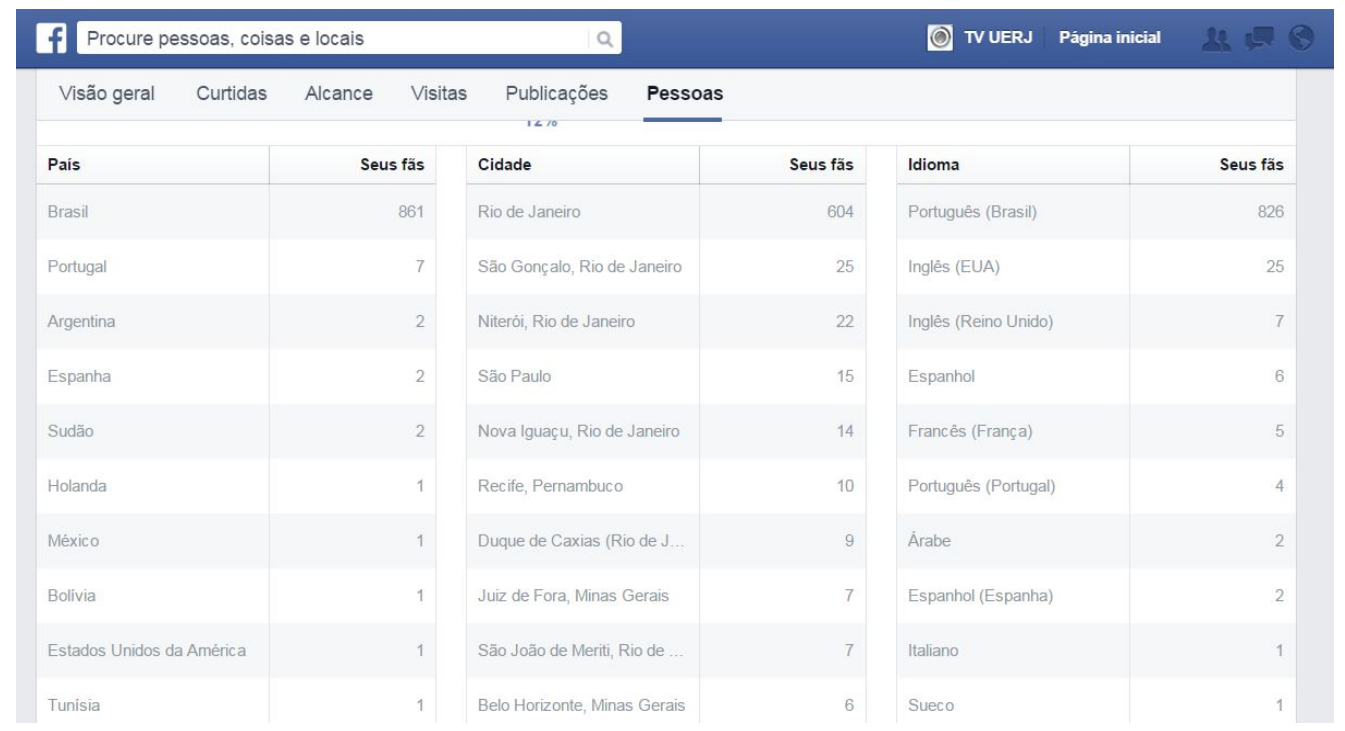

Figura [4]. Post do Facebook. País/Cidade/Idioma 


\section{Considerações finais}

Ao aportar na web, a TV Uerj vem propiciando novas formas de interação entre a Universidade e a sociedade em geral, bem como de produção e difusão de conteúdos. ${ }^{11}$ Surgem diferentes possibilidades para que a Universidade construa sua produção discursiva sobre questões da atualidade, fortalecendo sua inserção no debate público, assim como a visibilidade para suas iniciativas, atividades e projetos.

A TV Uerj insere-se entre as modalidades contemporâneas de comunicação e busca orientar seu trabalho por uma perspectiva de jornalismo colaborativo: o público é bem-vindo a participar, seja com opiniões e sugestões de pauta, seja pela produção de conteúdos próprios. Constitui um espaço de popularização da ciência, da cultura e do intercâmbio de saberes, para fortalecer uma prática institucional que valorize a construção do conhecimento para além dos limites do ambiente acadêmico.

Como atividade de extensão de caráter permanente, nutre-se da relação dialógica entre universidade e sociedade. Nessa dinâmica, os estudantes bolsistas participam de todas as etapas de produção dos programas e encontram ambiente favorável à experimentação, ao desenvolvimento de pesquisas e à observação da realidade, construindo consciência crítica acerca de sua formação profissional e humanista, bem como da importância social de sua própria atuação.

$\mathrm{Na}$ era do domínio imagético, as dimensões de espaço e tempo são ressignificadas. Nesse universo, cada indivíduo - e cada organização - explora múltiplas possibilidades de produzir e exibir seus próprios conteúdos multimídia. Postar, curtir, capturar, compartilhar, viralizar - na gramática digital, verbos que traduzem não só ações cotidianas como também novas formas de participação social, política e cultural. Ou, quem sabe, um novo tipo de conhecimento: pluriversitário.

"À medida que a ciência se insere mais na sociedade, esta insere-se mais na ciência. A universidade foi criada segundo um modelo de relações unilaterais com a sociedade e é esse modelo que subjaz à sua institucionalidade atual. $\mathrm{O}$ conhecimento 
pluriversitário substitui a unilateralidade pela interatividade, uma interatividade enormemente potenciada pela revolução nas tecnologias de informação e de comunicação". ${ }^{12}$

\section{Contribuições dos autores}

Ana Cláudia Theme coordenou o processo de concepção e implementação da TV Uerj e é autora do relato de experiência. Anderson Barreto é um dos criadores e diretores do programa Bonde Alegria, co-autor da parte referente ao programa. Guto Lacerda dirige o Programa Campus e foi responsável pela autoria da seção relacionada a essa produção.

\section{Referências}

1 SENNETT, Richard. O declínio do homem público: as tiranias da intimidade. São Paulo: Companhia das Letras, 1998. 250 p.

2 THOMPSON, John B. A mídia e a modernidade: uma teoria social da mídia. Petrópolis: Vozes, 1999. 180 p.

3 BOURDIEU, Pierre. O poder simbólico. São Paulo: Difusão Européia do Livro, 1989. $143 \mathrm{p}$.

4 CANCLINI, Nestor Garcia. Culturas híbridas - estratégias para entrar y salir de la modernidad. México: Grijalbo, 1990. 349 p.

5 PAVAN, Crodowaldo e KREINZ, Gloria. Os donos da paisagem. Estudos sobre divulgação científica. São Paulo: ECA-USP, 2000. 240 p.

6 Plano Nacional de Extensão Universitária. Edição atualizada. 2000/2001.

7 RAMALHO, Alzimar. Mapa da TV universitária brasileira: versão 3.0. Viçosa: Anadarco Comunicação, 2011.

8 CELLARD, André. A análise documental. In. Vários autores. A pesquisa qualitativa: enfoques epistemológicos e metodológicos. Petrópolis: Vozes, 2010.

9 TRAQUINA, Nelson. Teorias do Jornalismo. Florianópolis: Insular, 2004. 224 p 
10 MELO NETO, José Francisco de. Extensão Universitária: bases ontológicas. In. MELO NETO. José Francisco de (Org.) Extensão Universitária: diálogos populares. João Pessoa: EDUFPA, 2002.

11 CAPPARELLI, Sérgio; LIMA, Venicio A de. Comunicação e televisão: desafios da pósglobalização. São Paulo: Hacker, 2004. 162 p.

12 SANTOS, Boaventura de Sousa. A universidade no século XXI: para uma reforma democrática e emancipatória da Universidade. São Paulo: Cortez, 2004. 